\title{
Kajian Jembatan Beton Prategang di Muara Klukup Bentang 32 Meter
}

\author{
Exacta Lovendays Simamora, Suhendra*, Annisaa Dwiretnani \\ Program Studi Teknik Sipil Universitas Batanghari Jambi \\ *Correspondence email: suhendra_domas@yahoo.com
}

\begin{abstract}
Abstrak. Penelitian ini bertujuan untuk mengkaji perhitungan struktur jembatan klukup yang berlokasi di Desa Kelukup, Kecamatan Merangin, Kabupaten Merangin, Provinsi Jambi. Struktur jembatan berupa beton bertulang, dan beton prategang. Referensi yang digunakan adalah AASHTO LRFD Bridge Design Specifications, MKB No. 009/BM/2008, RSNI T-12-2004, SKBI-1328- 1987, SNI 03-2847-2002, SNI 2847-2013, SNI 1727-2013, SNI 2833-2016, SNI 2052:2017 dan Peraturan Pembebanan Untuk Jembatan SNI 1725:2016. Alat bantu perhitungan dalam penelitian ini adalah Aplikasi SAP2000 V 20 dan Microsoft Excel. Hasil kajian menunjukkan bahwa perhitungan struktur jembatan adalah di dapat hasil perhitungan 4 buah lubang tendon, memiliki 2 tipe balok girder yaitu balok girder lapangan dan balok girder tumpuan, memiliki 2 di mensi balok diafragma, system prategang mengunakan sistem Pasca-Tarik dan stressing satu arah.
\end{abstract}

Kata Kunci: Jembatan; Beton Prategang

\section{PENDAHULUAN}

Dengan perkembangan penduduk pada saat ini, maka dibutuhkan penambahan infrastruktur jalan ataupun peremajaan infrastruktur yang sudah ada demi menunjang lancarnya mobilitas warga secara tidak langsung akan berdampak pada pengembangan wilayah. Pada dasarnya peremajaan atau revitalisasi jembatan perlu dilakukan untuk memperbarui atau memperkuat struktur jembatan yang sudah ada, tetapi apabila suatu jembatan dirasa perlu di bangun ulang dengan mempertimbangkan umur dan muatan kendaraan dan juga struktur jembatan yang sudah tidak layak untuk di lewati.

Dengan mempertimbangkan hal tersebut maka jembatan Jalan Provinsi yang berada di Desa Kelukup, Kecamatan Merangin, Kabupaten Merangin, Provinsi Jambi, dilaksanakan oleh Dinas Pekerjaan Umum dan Perumahan Rakyat Provinsi Jambi semata-mata untuk meningkatkan pelayanan terhadap pengguna jalan. Struktur jembatan yang lama tidak di bongkar agar tetap bisa mendukung mobilisasi masyarakat sekitar lokasi proyek jembatan. Jembatan Muara Kelukup yang dilaksanakan oleh Dinas Pekerjaan Umum Provinsi Jambi mempunyai bentang 32 meter dan mempunyai lebar jembatan 7,9 meter dan dilengkapi trotoar selebar 0,5 meter.

Post-tension adalah Tendon dan beton ( dengan tulangan ) dimasukkan kedalam sebuah bekisting dan kemudian dilakukan pengecoran. Setelah beton mencapai mencapai kekuatan seperlunya, maka dilakukan pemberian gaya prategang sampai dengan kekuatan yang diinginkan ( biasanya dilihat dari manometer ). Lalu, tendon di tarik di dua sisi dan diangkur secara bersamaan dan diputus yang akan mengakitbatkan adanya gaya tekan pada defleksi arah keatas. Sistem inilah yang digunakan dalam stressing PCI I Girder pada proyek jembatan di Muara Klukup bentang 7,9 meter. Penguna sistem Post-tension dipilih karena pertimbangan, keterbatasan lahan diproyek Muara Kelukup agar tidak mengangu aktifitas masyarakat disekitar. Dibutuhkan bentuk tendon yang melengkung dengan panjang balok girder 31,6 meter, maka pengunaan sistem akan lebih murah dalam hal bekisting.

Kemudahan dalam pekerjaan dan tidak banyak mengunakan waktu. Pemilihan penampang I girder, metode stressing dengan sistem post-tension, kebutuhan tulangan, dan kabel strand telah sesuai dengan hasil perhitungan dalam perencanaan tetapi pada pelaksanaan gambar perencanaan tidak sesuai di waktu pelaksanaan proyek.. Adapun pembebanan yang bekerja pada struktur antara lain sebagai berikut :

1. Beban Mati (Dead Loads)

a. Berat Sendiri ( MS )

Menurut SNI 1725:2016 beban sendiri adalah berat bagian tersebut dan elemen-elemen structural lain yang dipikulnya, termasuk dalam hal ini berat bahan dan bagian jembatan yang merupakan elemen struktural, ditambah dengan elemen nonstuktural yang diangap tetap.

b. Beban Mati Tambahan ( MA )

Menurut SNI 1725:2016 beban mati tambahan adalah berat seluruh bahan yang membentuk suatu beban pada jembatan yang merupakan elemen nonstruktural, dan besarnya dapat berubah selama umur jembatan.

2. Beban Hidup (Live Loads)

Menurut SNI 1725:2016 beban hidup adalah beban bergerak yang bersifat tetap dan dinamis antara lain beban pejalan kaki, beban BGT, BTR, bean truk, gaya rem, beban tumbukan kendaraan dan tidak termasuk beban konstruksi dan beban lingkungan seperti beban angin, beban hujan, beban gempa, beban banjir, atau beban mati.

3. Beban Angin (Wind Loads) 
Beban angin ialah semua beban yang bekerja pada sttruktur jembatan baik struktur atas maupun struktur bawah yang disebabkan oleh selisih dalam tekanan. Menurut SNI 1725:2016 penentuan parameter dasar untuk penentuan beban angin antara lain;

a. Kecepatan angin rencana pada elevasi rencana;

b. Kecepatan angin pada elevasi $10000 \mathrm{~mm}$ diatas permukaan tanah dan permukaan air laut;

c. Kecepatan gesekan angin;

d. Panjag gesekan dihulu jembatan;

e. Tekanan angin dasar;

4. Beban Gempa

Menurut SNI 2833-2016 pengaruh gempa rencana yang harus ditinjau dalam perencanaan dan evaluasi struktur bangunan gedung dan non gedung serta berbagai bagian dan peralatannya secara umum. Gempa rencana ditetapkan sebagai gempa dengan kemungkinan terlewati besarnya selama umur struktur lama bangunan 50 tahun adalah $>2 \%$. Kombinasi pembebanan adalah kekuatan perlu yang dibutuhkan suatu komponen struktur untuk menahan beban terfakor yang bekerja dengan berbagai kombinasi efek beban disebutkan kuat perlu (U), kuat perlu adalah kekuatan suatu komponen struktur atau penampang yang diperlukan untuk menahan beban terfaktor atau momen dengan gaya dalam, faktor keamanan kombinasi pembebanan yang diisyaratkan oleh SNI 1725:2016.

\section{METODE}

1. Beban

Metode yang digunakan untuk pembebanan berdasarkan SNI 1725:2016 Pembebanan Untuk Jembatan. Badan Standarisasi Nasional Jakarta.

2. Klasifikasi beban gempa

Pedoman yang digunakan adalah SNI 2833-2016. 2016. Perencanaan Jembatan Terhadap Beban Gempa. Badan Standarisasi Nasional Jakarta

3. Alat bantu yang digunakan

Alat bantu yang digunakan dalam perhitungan ini yaitu SAP2000 V 20, Microsoft Excel,

Secara ringkas penelitian ini bisa dilihat pada bagan alir penelitian berikut:

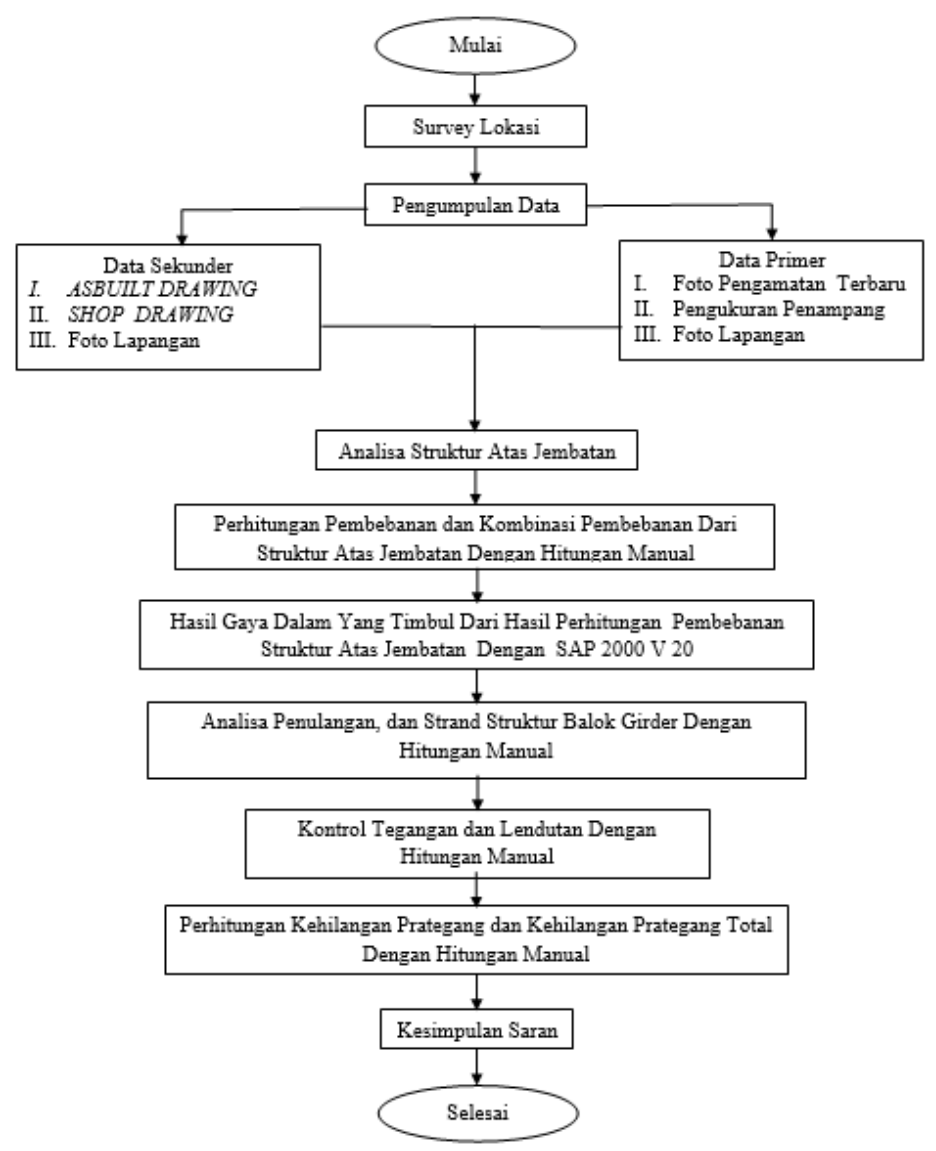

Sumber : Data Olahan (2020)

Gambar 1. Diagram Alir Penelitian 
Exacta Lovendays Simamora, Suhendra dan Annisaa Dwiretnani, Kajian Jembatan Beton Prategang di Muara Klukup Bentang 32 Meter

Secara ringkas kehilangan prateang ini bisa dilihat pada bagan dibawah ini :

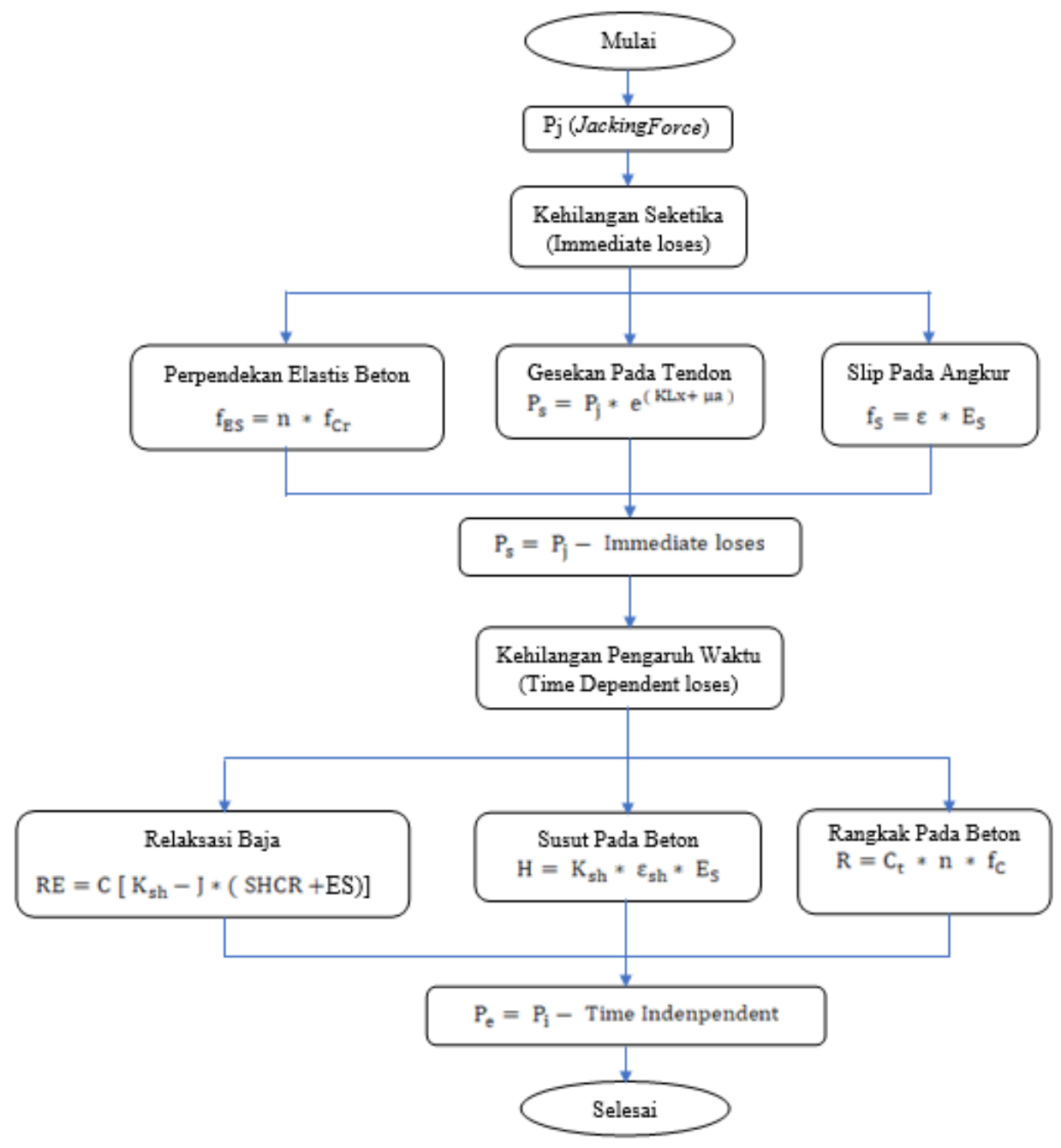

Sumber : Data Olahan (2020)

Gambar 2. Diagram Alir Kehilangan Prategang

\section{HASIL DAN P[EMBAHASAN}

Tabel 1. Rekap Hasil Perhitungan Peulangan Struktur Atas

\begin{tabular}{clcc}
\hline No. & \multicolumn{1}{c}{ Posisi Tulangan } & Tulangan Pokok & Tulangan Sengkang \\
\hline 1. & Parapet & D13-100 & D13-200 \\
2. & Lantai Jembatan & D16-150 & D15-300 \\
3. & Rc Pelat & D13-200 & D13-250 \\
4. & Difragma Tumpuan & D13-600 & 5 D13 \\
5. & Difragma Lapangan & D13-600 & 6 D13 \\
\hline
\end{tabular}

Sumber : Data Olahan (2020)

Tabel 2. Hasil Perhitungan kehilangan prategang dari 5 persamaan

\begin{tabular}{cccccc}
\hline $\mathrm{e}$ & $1 / \mathrm{Pi}(2.67)$ & $1 / \mathrm{Pi}(2.68)$ & $1 / \mathrm{Pi}(2.69)$ & $1 / \mathrm{Pi}(2.70)$ & $1 / \mathrm{Pi}(2.71)$ \\
\hline-500 & $-1,434 \mathrm{E}-07$ & $-1,426 \mathrm{E}-08$ & $-1,652 \mathrm{E}-08$ & $-3,559 \mathrm{E}-07$ & $-2,756 \mathrm{E}-07$ \\
0 & $-6,122 \mathrm{E}-08$ & $3,760 \mathrm{E}-08$ & $4,355 \mathrm{E}-08$ & $-1,519 \mathrm{E}-07$ & $-1,176 \mathrm{E}-07$ \\
500 & $2,099 \mathrm{E}-08$ & $8,946 \mathrm{E}-08$ & $1,036 \mathrm{E}-07$ & $5,208 \mathrm{E}-08$ & $4,033 \mathrm{E}-08$ \\
1000 & $1,032 \mathrm{E}-07$ & $1,413 \mathrm{E}-07$ & $1,637 \mathrm{E}-07$ & $2,560 \mathrm{E}-07$ & $1,983 \mathrm{E}-07$ \\
1500 & $1,854 \mathrm{E}-07$ & $1,932 \mathrm{E}-07$ & $2,237 \mathrm{E}-07$ & $4,600 \mathrm{E}-07$ & $3,563 \mathrm{E}-07$ \\
2000 & $2,676 \mathrm{E}-07$ & $2,450 \mathrm{E}-07$ & $2,838 \mathrm{E}-07$ & $6,640 \mathrm{E}-07$ & $5,143 \mathrm{E}-07$ \\
2500 & $3,498 \mathrm{E}-07$ & $2,969 \mathrm{E}-07$ & $3,439 \mathrm{E}-07$ & $8,680 \mathrm{E}-07$ & $6,723 \mathrm{E}-07$ \\
3000 & $4,320 \mathrm{E}-07$ & $3,488 \mathrm{E}-07$ & $4,039 \mathrm{E}-07$ & $1,072 \mathrm{E}-06$ & $8,302 \mathrm{E}-07$ \\
\hline
\end{tabular}

Sumber : Data Olahan (2020) 
Exacta Lovendays Simamora, Suhendra dan Annisaa Dwiretnani, Kajian Jembatan Beton Prategang di Muara Klukup Bentang 32 Meter

Tabel 3. Tata Letak Posisi Kabel Tendon

\begin{tabular}{|c|c|c|c|c|c|}
\hline \multirow{2}{*}{ Jarak X ( mm ) } & \multirow{2}{*}{ Trace Z0 ( mm ) } & \multicolumn{4}{|c|}{ Posisi Masing-Masing Kabel } \\
\hline & & $\mathrm{Z} 1(\mathrm{~mm})$ & $\mathrm{Z} 2(\mathrm{~mm})$ & $\mathrm{Z} 3(\mathrm{~mm})$ & $\mathrm{Z} 4(\mathrm{~mm})$ \\
\hline 0 & 709 & 1180 & 920 & 660 & 400 \\
\hline 1200 & 621 & 1049 & 800 & 580 & 361 \\
\hline 3000 & 501 & 872 & 638 & 473 & 307 \\
\hline 4850 & 395 & 715 & 494 & 377 & 260 \\
\hline 5000 & 387 & 703 & 483 & 370 & 256 \\
\hline 6000 & 337 & 629 & 415 & 325 & 234 \\
\hline 7000 & 292 & 563 & 354 & 284 & 214 \\
\hline 8500 & 234 & 476 & 275 & 231 & 188 \\
\hline 9000 & 217 & 451 & 252 & 216 & 180 \\
\hline 10000 & 186 & 406 & 210 & 188 & 166 \\
\hline 11000 & 161 & 368 & 176 & 165 & 155 \\
\hline 12150 & 137 & 333 & 144 & 144 & 144 \\
\hline 13000 & 124 & 313 & 126 & 132 & 138 \\
\hline 14000 & 113 & 297 & 111 & 122 & 134 \\
\hline 15800 & 105 & 285 & 100 & 115 & 130 \\
\hline 16000 & 105 & 285 & 100 & 115 & 130 \\
\hline 17000 & 108 & 290 & 105 & 118 & 132 \\
\hline 18000 & 117 & 302 & 116 & 126 & 135 \\
\hline 1945 & 569 & 973 & 731 & 534 & 338 \\
\hline 20000 & 148 & 348 & 158 & 154 & 149 \\
\hline 21000 & 170 & 382 & 189 & 174 & 159 \\
\hline 22000 & 198 & 423 & 226 & 199 & 172 \\
\hline 2310 & 545 & 937 & 698 & 512 & 327 \\
\hline 24000 & 268 & 526 & 321 & 262 & 203 \\
\hline 25000 & 310 & 588 & 378 & 300 & 222 \\
\hline 2675 & 522 & 903 & 666 & 491 & 316 \\
\hline 27000 & 409 & 735 & 512 & 389 & 266 \\
\hline 28000 & 465 & 819 & 589 & 440 & 291 \\
\hline 29000 & 527 & 910 & 672 & 495 & 318 \\
\hline 30400 & 621 & 1049 & 800 & 580 & 361 \\
\hline 31600 & 709 & 1180 & 920 & 660 & 400 \\
\hline
\end{tabular}

Sumber: Data Olahan (2020)

Tabel 4. Hasil Perhitungan Kehilangan Prategang Total

\begin{tabular}{clc}
\hline No & Kehilangan Prategang Total & Besar Kehilangan ( \% ) \\
\hline 1 & Perpendekan Elastis Beton & $3,75 \%$ \\
2 & Akibat Pengaruh Rangkak & $3,09 \%$ \\
3 & Akibat Pengaruh Susut & $5,72 \%$ \\
4 & Akibat Pengaruh Kabel Tendon & $4,91 \%$ \\
& & $17,5 \%$ \\
\hline
\end{tabular}

Sumber: Data Olahan (2020)

Tabel 5. Hasil Perhitungan Lendutan Total

\begin{tabular}{clccc}
\hline No. & Jenis Beban & Kode Beban & Lendutan $(\mathrm{m})$ & Keterangan \\
\hline A & Lendutan ke atas & Lendutan ke bawah & $-0,00104$ & Chamber \\
B & & MS & 0,00944 & Deflection \\
1 & Pelat Lantai & MS & 0,00298 & Deflection \\
2 & Pelat Deck & MS & 0,00629 & Deflection \\
3 & Diafragma & MA & Deflection \\
4 & Air & TD & 0,00085 & Deflection \\
5 & BTR & TD & 0,01372 & Deflection \\
6 & BGT & TB & 0,01474 & Deflection \\
7 & REM & TP & 0,01474 & Deflection \\
8 & Pejalan Kaki & & 0,04253 & 0,10425 \\
\end{tabular}

Sumber: Data Olahan (2020) 
Exacta Lovendays Simamora, Suhendra dan Annisaa Dwiretnani, Kajian Jembatan Beton Prategang di Muara Klukup Bentang 32 Meter

Tabel 6. Hasil Perhitungan Kebutuhan Tulangan Tendon 1

\begin{tabular}{|c|c|c|c|}
\hline Momen Brusting Vertikal & Desain & Keterangan & Lokasi \\
\hline Besar Momen & 70,55 & & \\
\hline Tulangan Desain & 1647,06 & & \\
\hline Set Tulangan & & 265,464579 & \\
\hline Panjang Daerah Sengkang & 440 & & \\
\hline Jumlah Sengkang & 6,20444 & 7 & \\
\hline Spasi Sengkang & 62,8571 & 50 & \\
\hline Lokasi Sengkang ke 1 & 110 & 100 & \\
\hline Momen Spaling & Desain & Keterangan & \\
\hline Besar Momen & 21,62 & & \\
\hline Tulangan Desain & 105,98 & & \\
\hline Set Tulangan & & 265,464579 & \\
\hline Panjang Daerah Sengkang & 320 & & Tendon 1 \\
\hline Jumlah Sengkang & 0,39922 & 1 & \\
\hline Spasi Sengkang & 320 & 300 & \\
\hline Lokasi Sengkang ke 1 & 200 & Selimut Beton & \\
\hline Momen Brusting Horizontal & Desain & Keterangan & \\
\hline Besar Momen & 69,86 & & \\
\hline Tulangan Desain & 996,26 & & \\
\hline Set Tulangan & & 265,464579 & \\
\hline Panjang Daerah Sengkang & 440 & & \\
\hline Jumlah Sengkang & 3,75289 & 4 & \\
\hline Spasi Sengkang & 117,243 & 100 & \\
\hline Lokasi Sengkang ke 1 & 110 & 100 & \\
\hline
\end{tabular}

Sumber: Data Olahan (2020)

Tabel 7. Hasil Perhitungan Kebutuhan Tulangan Tendon 2

\begin{tabular}{|c|c|c|c|}
\hline Momen Brusting Vertikal & Desain & Keterangan & Lokasi \\
\hline Besar Momen & 279,56 & & \\
\hline Tulangan Desain & 1612,22 & & \\
\hline Set Tulangan & & 265,464579 & \\
\hline Panjang Daerah Sengkang & 440 & & \\
\hline Jumlah Sengkang & 6,1 & 7 & \\
\hline Spasi Sengkang & 62,85714286 & 50 & \\
\hline Lokasi Sengkang ke 1 & 110 & 100 & \\
\hline Momen Spaling & Desain & Keterangan & \\
\hline Besar Momen & 121,65 & & \\
\hline Tulangan Desain & 596,32 & & \\
\hline Set Tulangan & & 265,464579 & \\
\hline Panjang Daerah Sengkang & 320 & & Tendon 2 \\
\hline Jumlah Sengkang & 2,246336161 & 3 & \\
\hline Spasi Sengkang & 106,6666667 & 100 & \\
\hline Lokasi Sengkang ke 1 & 200 & Selimut Beton & \\
\hline Momen Brusting Horizontal & Desain & Keterangan & \\
\hline Besar Momen & 69,86 & & \\
\hline Tulangan Desain & 996,26 & & \\
\hline Set Tulangan & & 265,464579 & \\
\hline Panjang Daerah Sengkang & 440 & & \\
\hline Jumlah Sengkang & 3,752886241 & 4 & \\
\hline Spasi Sengkang & 117,2430955 & 100 & \\
\hline Lokasi Sengkang ke 1 & 110 & 100 & \\
\hline
\end{tabular}

Sumber: Data Olahan (2020) 
Exacta Lovendays Simamora, Suhendra dan Annisaa Dwiretnani, Kajian Jembatan Beton Prategang di Muara Klukup Bentang 32 Meter

Tabel 8. Hasil Perhitungan Kebutuhan Tulangan Tendon 3

\begin{tabular}{|c|c|c|c|}
\hline Momen Brusting Vertikal & Desain & Keterangan & Lokasi \\
\hline Besar Momen & 266,10 & & \\
\hline Tulangan Desain & 1581 & & \\
\hline Set Tulangan & & 265,4645792 & \\
\hline Panjang Daerah Sengkang & 440 & & \\
\hline Jumlah Sengkang & 5,955886131 & 6 & \\
\hline Spasi Sengkang & 73,87649635 & 50 & \\
\hline Lokasi Sengkang ke 1 & 110 & 100 & \\
\hline Momen Spaling & Desain & Keterangan & \\
\hline Besar Momen & 121,9453114 & & \\
\hline Tulangan Desain & 597,7711344 & & \\
\hline Set Tulangan & & 265,4645792 & \\
\hline Panjang Daerah Sengkang & 320 & & Tendon 3 \\
\hline Jumlah Sengkang & 2,251792447 & 3 & \\
\hline Spasi Sengkang & 106,6666667 & 100 & \\
\hline Lokasi Sengkang ke 1 & 200 & Selimut Beton & \\
\hline Momen Brusting Horizontal & Desain & Keterangan & \\
\hline Besar Momen & 69,86 & & \\
\hline Tulangan Desain & 996,26 & & \\
\hline Set Tulangan & & 265,4645792 & \\
\hline Panjang Daerah Sengkang & 440 & & \\
\hline Jumlah Sengkang & 3,752886241 & 4 & \\
\hline Spasi Sengkang & 117,2430955 & 100 & \\
\hline Lokasi Sengkang ke 1 & 110 & 100 & \\
\hline
\end{tabular}

Sumber: Data Olahan (2020)

Tabel 9. Hasil Perhitungan Kebutuhan Tulangan Tendon 4

\begin{tabular}{|c|c|c|c|}
\hline Momen Brusting Vertikal & Desain & Keterangan & Lokasi \\
\hline Besar Momen & 104,90 & & \\
\hline Tulangan Desain & 1028,48 & & \\
\hline Set Tulangan & & 265,4645792 & \\
\hline Panjang Daerah Sengkang & 440 & & \\
\hline Jumlah Sengkang & 3,874257549 & 4 & \\
\hline Spasi Sengkang & 110 & 100 & \\
\hline Lokasi Sengkang ke 1 & 110 & 100 & \\
\hline Momen Spaling & Desain & Keterangan & \\
\hline Besar Momen & 36,47400124 & & \\
\hline Tulangan Desain & 178,7941237 & & \\
\hline Set Tulangan & & 265,4645792 & \\
\hline Panjang Daerah Sengkang & 320 & & Tendon 4 \\
\hline Jumlah Sengkang & 0,673514049 & 1 & \\
\hline Spasi Sengkang & 320 & 300 & \\
\hline Lokasi Sengkang ke 1 & 200 & Selimut Beton & \\
\hline Momen Brusting Horizontal & Desain & Keterangan & \\
\hline Besar Momen & 69,86 & & \\
\hline Tulangan Desain & 996,26 & & \\
\hline Set Tulangan & & 265,4645792 & \\
\hline Panjang Daerah Sengkang & 440 & & \\
\hline Jumlah Sengkang & 3,752886241 & 4 & \\
\hline Spasi Sengkang & 117,2430955 & 100 & \\
\hline Lokasi Sengkang ke 1 & 110 & 100 & \\
\hline
\end{tabular}

Sumber: Data Olahan (2020)

\section{Pembahasan}

Dalam penyusunan Tugas Akhir struktur jembatan menggunakan konstruksi beton bertulang dan beton prategang. Untuk menganalisis struktur jembatab penulis berpedoman pada peraturan-peraturan yang berlaku di 
Indonesia. Selain itu juga mengunakan perangkat lunak (software) komputer yang membantu dalam proses perhitungan yaitu SAP2000 V 20

Spesifikasi Bangunan Stuktur Meliputi :

1. Bentang Jembatan : $32 \mathrm{~m}$

2. Panjang Balok Girder : $31,6 \mathrm{~m}$

3. Lebar Jembatan : $9 \mathrm{~m}$

4. Jumlah Lajur : 2 Lajur

5. Lebar lajur : $3 \mathrm{~m}$

6. Dimensi Trotoar : $0,25 \times 0,50 \times 31 \mathrm{~m}$

7. Mutu Beton Trotoar : K 175

8. Dimensi Kerb : 0,15 x 0,13 x 0,25 m

9. Mutu Beton Kerb : K 300

10. Lebar Pagar tepi : $0,20 \mathrm{~m}$

11. Mutu Beton Pagar Tepi : K 250

12. Tebal plat lantai jembatan : $0,25 \mathrm{~m}$

13. Mutu Beton plat lantai : K 350

14. Mutu Beton Balok Girder : K 500

15. Rc Plat / Deck Slab : 0,1 x 1,45 × 2 m

16. Mutu Beton Rc Plat : K 135

17. Tinggi Genangan Air Hujan : $0,10 \mathrm{~m}$

18. Mutu Beton Diafragma: K 250

19. Jenis Strands : Uncoated 7 wire super strands ASTM A-416 grade 270

20. Lokasi: Desa Kelukup, Kecamatan Merangin, Kabupaten Merangin, Provinsi Jambi.

\section{SIMPULAN}

Adapun kesimpulan yang didapat dirangkumkan berdasarkan hasil perhitungan adalah sebagai berikut:

1. Raling post, besi pelat dan baut besi pelat yang ada di gambar dengan jarak 1,5 m dengan pipa sandaran $\emptyset 3$ inchi panjang 32 meter, sedangkan yang dilapangan raling post, besi pelat dan baut besi pelat yang ada di gambar dengan jarak $2 \mathrm{~m}$ dengan pipa sandaran $\emptyset 3$ inchi dengan panjang $32 \mathrm{M}$ dengan penutup pipa $\emptyset 4$ inchi dengan $\mathrm{p}$ $0,05 \mathrm{~cm}$

2. Parapet jembatan yang ada di gambar dengan dimensi 0,6 x 1,6 x $32 \mathrm{~m}$ dengan tulangan utama D13-200 mm dan tulangan geser D13-150 mm, hasil perhitungan parapet jembatan dengan dimensi 0,6 x 1,6 x $32 \mathrm{~m}$ dengan tuangan utama D13-100 mm dan tulangan geser D13-100 mm

3. Slab lantai trotoar yang ada digambar dengan dimensi $0,27 \times 0,5 \times 32 \mathrm{~m}$ dengan tulangan utama yang digunakan D16-200 mm dan tulangan geser D16-300 mm, hasil perhitungan slab trotoar dengan dimensi 0,32 x 0,5 x $32 \mathrm{~m}$ dengan tulangan utama 10D16 - 100 dan tulangan geser D16 - 400

4. Slab lantai jembatan yang ada digambar dengan dimensi $0,25 \times 7,9 \times 32 \mathrm{~mm}$ dengan tulangan utama yang digunakan D16-200 $\mathrm{mm}$ dan tulangan geser D16-300 mm, hasil perhitungan slab lantai jembatan dengan dimensi 0,25 x 7,9 x $32 \mathrm{~mm}$ dengan tulangan utama yang digunakan D16-130 mm dan tulangan geser D16-180 mm

5. Pelat deck yang ada di gambar dengan dimensi $0,07 \times 1,45 \times 1 \mathrm{~m}$ dengan luas $0,102 \mathrm{~m}$, tulangan yang di gunakan tulangan utama D13-200 dan tulangan geser D13-20, pelat deck hasil perhitungan dengan dimensi 0,1 x 1,45 x 2 $\mathrm{m}$ dengan luas 0,29 $\mathrm{m}$, tulangan utama yang digunakan D13-150 mm dan tulangan geser D13-200 mm

6. Balok diafragma yang lokasi lapangan ada 2 jenis dengan masing-masing dimensi yang berbeda. Balok diafragma yang ada di lokasi lapangan antara lain .

a. Diafragma tumpuan dengan dimensi $0,2 \times 0,75 \times 1,3 \mathrm{~m}$ dengan luas diafragma $0,195 \mathrm{~m}$, tulangan yang digunakan tulangan utama 5D13 dan tulangan geser D13-600 mm.

b. Diafragma lapangan dengan dimensi $0,2 \times 0,8 \times 1,3 \mathrm{~m}$ dengan luas diafragma $0,208 \mathrm{~m}$, tulangan yang digunakan tulangan utama 9D13 dan tulangan geser D13-600 mm.

7. Balok diafragma yang ada di asbuilt drawing dan shop drawing dengan dimensi $0,2 \times 1,25 \times 2,6 \mathrm{~m}$ dengan luas diafrgama $0,65 \mathrm{~m}$, tulangan yang digunakan tulangan utama 7 × 2 D13 dengan tulangan geser 7D13

8. Tendon untuk balok prategang yang ada di gambar asbuilt drawing dan shop drawing berjumlah 6 buah tetapi setelah di perhitungkan di dapatkan tendon dengan jumlah 4 buah sesuai dengan foto dokumentasi dan foto survey lapangan.

9. End block tendon yang ada di gambar asbuilt drawing dan shop drawing dengan dimensi $40 \times 40 \mathrm{~cm}$ tetapi setelah di perhitungkan dimensi end block tendon $20 \times 20 \mathrm{~cm}$ 
10. Diameter tendon yang ada di asbuilt drawing dan shop drawing adalah D 17 setelah di perhitungkan diameterya D 10 dengan jumlah strand kabel pada tendon 1 berjumlah 12 buah dan untuk tendon 2- 4 berjumlah 20 strand kabel

11. Tulangan Brusting yang ada di asbuilt drawing dan shop drawing berjumlah 7- 11 buah tetapi setelah di perhitungkan jumlah tulangan brusting vertikal berjumlah 7, brusting horizontal 4 dan tulangan spaling berjumlah 3

\section{Saran}

Adapun saran yang dapat disampaikan oleh penulis dalam Tugas Akhir ini adalah:

1. Menggunakan peraturan yang tepat diusahakan mengunakan peraturan terbaru sehingga selalu mengikuti perkembangan dunia konstruksi.

2. Untuk pelaksanaan dalam mengunakan tulangan dan kabel tendon beton prategang harus sesuai dengan perhitungan perencanaan dan kondisi lapangan di karenakan tulangan dan kabel tendon beton prategang yang ada di gambar tidak sesuai dengan lapangan maka dari itu harus perlu di hitung kembali sesuai dengan kebutuhan dilapangan agar struktur jembatan tidak mengalami keurangan kekuatan pada struktur dan tidak boros dalam penggunaan tulangan dan kabel tendon.

3. Bagi para pembaca yang ingin merencanakan suatu jembatann beton prategang pemilihan tulangan dan kabel tendon sangatlah penting dari segi aspek ukuran tulangan dan kabel tendon jangan terlalu banyak digunakan harusalah di sesuaikan dengan dilapangan agar menjadi lebih ekonomis dan menghindari boros dalam pengunaan tulangan dan kabel tendon.

\section{DAFTAR PUSTAKA}

AASHTO LRFD Bridge Design Specifications, 2012. American Association of State Highway and Transportation Officials

RSNI T-12-2004. 2004. Perencanaan Sturktur Beton Untuk Jembatan. Badan Standarisasi Nasional Jakarta.

SKBI-1328- 1987 Pedoman Perencanaan Pembebanan Jembatan Jalan Raya. Dinas Pekerjaan Umum Nasional Jakarta.

SNI 03-2847-2002. 2002. Tatat Cara Perhitungan Struktur Beton Untuk Bangunanan Gedung. Badan Standarisasi Nasional Jakarta.

SNI 2847-2013. 2013. Persyaratan Beton Struktural Untuk Bangunan Gedung. Badan Standarisasi Nasional Jakarta.

SNI 1727-2013. 2013. Beban Minimum Untuk Perancangan Bangunan Gedung dan Struktur Lain. Badan Standarisasi Nasional Jakarta.

SNI 1725:2016. 2016. Pembebanan Untuk Jembatan. Badan Standarisasi Nasional Jakarta.

SNI 2833-2016. 2016. Perencanaan Jembatan Terhadap Beban Gempa. Badan Standarisasi Nasional Jakarta.

SNI 2052-2017. 2017. Baja Tulangan Beton. Badan Standarisasi Nasional Jakarta.

SNI 2052:2017. Baja Tulangan Beton. Badan Standarisasi Nasional Jakarta. 